\title{
MicroRNA-210 induces apoptosis
} in colorectal cancer via induction of reactive oxygen

\author{
Katrin E. Tagscherer ${ }^{1,2,3^{*}}$, Anne Fass1 ${ }^{1,2,4,5}$, Tabea Sinkovic ${ }^{1,2}$, Jutta Richter ${ }^{1,2,3}$, Sabrina Schecher ${ }^{1,2,3}$, \\ Stephan Macher-Goeppinger ${ }^{1,2,3}$ and Wilfried Roth ${ }^{1,2,3}$
}

\begin{abstract}
Background: Deregulation of miRNA-210 is a common event in several types of cancer. However, increased expression levels in the cancer tissue have been associated with both poor and good prognosis of patients. Similarly, the function of miR-210 with regard to cell growth and apoptosis is still controversial.

Methods: Overexpression of miR-210 was performed in HCT116, SW480 and SW707 colorectal cancer (CRC) cell lines. Functional effects of a modulated miR-210 expression were analyzed with regard to proliferation, clonogenicity, cell cycle distribution, reactive oxygen species (ROS) generation, and apoptosis. Furthermore, quantitative real time (RT)-PCR and immunoblot analyses were performed to investigate signaling pathways affected by miR-210.

Results: We show that in CRC cells miR-210 inhibits clonogenicity and proliferation which was accompanied by an accumulation of cells in the G2/M phase of the cell cycle. Additionally, overexpression of miR-210 results in an increase of ROS generation. Moreover, miR-210 mediated the induction of apoptosis which was associated with an upregulation of pro-apoptotic Bim expression and enhanced processing of Caspase 2. Importantly, inhibition of ROS generation rescued cells from miR-210-induced apoptosis.
\end{abstract}

Conclusions: Taken together, miR-210 induces apoptosis in CRC cells via a ROS-dependent mechanism.

Keywords: miR-210, Colorectal carcinoma, ROS, Bim, Apoptosis

\section{Background}

Colorectal carcinoma (CRC) is the third most common cancer and one of the leading causes of death due to cancer world-wide [1]. Defects in the apoptosis signaling cascade account for resistance to therapy of malignant tumors. In the case of CRC this resistance to radio- and chemotherapy substantially contributes to a poor prognosis. So far, the molecular mechanisms underlying the varying degree of cell death resistance of CRC are largely unknown. Therefore, a better understanding of the regulation of survival and therapy resistance of CRC cells is urgently required.

\footnotetext{
*Correspondence: Katrin.Tagscherer@unimedizin-mainz.de

${ }^{3}$ Institute of Pathology, University Medical Center Mainz,

Langenbeckstraße 1, 55131 Mainz, Germany

Full list of author information is available at the end of the article
}

MicroRNAs (miRNAs) are short (20-23 nucleotides) non-coding mRNA molecules [2] functioning as posttranscriptional regulators of gene expression. Since miRNAs contribute to the regulation of different cellular processes involving apoptosis, cell cycle regulation and differentiation, their deregulation quite often results in tumorigenesis [3]. MiRNAs are transcribed as so-called pri-miRNAs, which are cleaved by Drosha in the nucleus [4]. The resulting microRNA precursor molecules (premiRNAs) are subsequently transported into the cytoplasm and processed to the mature miRNA by the Dicer complex [4]. The guide strand is integrated into the RISC complex resulting in the degradation of target mRNAs or their transcriptional inhibition [4]. MiRNAs were first discovered in 1993 by Lee et al. [5]. Since then, approx. 1400 human miRNAs have been discovered, amongst them almost 400 to be deregulated in CRC [6]. 
So far, it has been shown that miR-210 is upregulated in a variety of human cancers, including lung cancer [7-9], renal cell carcinoma [10-13], pancreatic carcinoma [14], breast cancer [15], hepatocellular carcinoma [16], colorectal carcinoma [17, 18] and adrenocortical carcinoma $[19,20]$. Besides, miR-210 is downregulated in squamous cell carcinoma [21] and ovarian cell carcinoma [22]. Although miR-210 overexpression is accompanied by a poor prognosis in many human tumors [15, 23-28], it has recently been shown, that high expression levels of miR-210 were significantly associated with an improved disease free survival in non-small cell lung cancer [29] and clear cell renal cell carcinoma post nephrectomy [30]. Similarly, low miR-210 expression levels were accompanied with a higher rate of relapse and a poorer treatment outcome in pediatric acute lymphoblastic leukemia [31]. Further, the function of miR-210 regarding the regulation of cell growth and apoptosis is quite controversial. Whereas some studies show that downregulation of miR-210 reduces viability in renal cell carcinoma [10], endothelial cells [32] and hepatoma [33], other studies claim that miR-210 acts in a pro-apoptotic manner in neuroblastoma [34], lung adenocarcinoma [35], renal cell carcinoma [36], esophageal squamous carcinoma [21] and lung adenocarcinoma [37].

In this study, we sought to explore the functional role of miR-210 with regard to apoptosis in CRC. We demonstrate that an increased expression of miR-210 reduces proliferation, cell cycle progression and colony formation. Furthermore, overexpression of miR-210 induces ROS generation and apoptosis, accompanied by an increased Bim expression and Caspase 2 processing. Taken together our results identify miR-210 as a potent inducer of apoptotic cell death in CRC and suggest the miR-210-induced ROS generation to be a possible key player within this process.

\section{Results}

\section{miR-210 overexpression influences CRC growth}

The role of miR-210 in the regulation of cell growth and death is quite controversial. Whereas some studies show that downregulation of miR-210 reduces viability in renal cell carcinoma [10], endothelial cells [32] and hepatoma [33], other studies claim miR-210 to act in a pro-apoptotic manner [21, 34-37]. To characterize the functional relevance of miR-210 in CRC we analyzed the effects of an increased expression of miR-210 on cell growth. To this end, we transfected colorectal cancer cell lines with a miR-210 precursor oligonucleotide (pre-miR-210; Additional file 1: Figure S1). Overexpression of exogenous miR-210 resulted in a significant reduction of proliferation (Fig. 1a) which was accompanied by a decrease of cells in the G1 phase and an accumulation of cells in the
G2 phase of the cell cycle (Fig. 1b). In line with these results, miR-210 overexpression reduced clonogenicity (Fig. 1c).

\section{miR-210 overexpression induces apoptosis}

To further functionally analyze the effects of increased miR-210 expression levels, we investigated the impact of miR-210 on cell death. Overexpression of miR-210 potently induced apoptotic cell death (Fig. 2a; Additional file 2: Figure S2), which was accompanied by cleavage of Caspase 3 (Fig. 2b). To characterize miR-210 mediated apoptosis, we analyzed the expression levels of different pro- and anti-apoptotic proteins. Immunoblot analyses revealed a consistent downregulation of the anti-apoptotic $\mathrm{Mcl}-1$ protein and an upregulation of the pro-apoptotic Bim protein upon miR-210 overexpression in all cell lines examined. The expression levels of other pro- or anti-apoptotic proteins which have additionally been analyzed, were not or only marginally affected (Fig. 2c). MiR-210 mediated upregulation of Bim involves transcriptional mechanisms as demonstrated by quantitative PCR analyses of Bim mRNA (Fig. 2d). Since the AKT pathway is known to regulate Bim expression on the transcriptional level via FOXO transcription factors [38], we were interested whether this pathway is likewise affected by miR-210. As a matter of fact, immunoblot analysis revealed that the AKT pathway is less activated in cells overexpressing miR-210 compared to control cells (Fig. 2e), pointing to an involvement of AKT in the regulation of Bim.

Further, we investigated the impact of Bim and Mcl-1 on miR-210 mediated apoptosis. To this end, we simultaneously transfected miR-210 oligonucleotides and different siRNAs targeting Bim mRNA, which should counteract the pro-apoptotic effect of miR-210. Surprisingly, knockdown of Bim did not (HCT116) or only marginally (SW480 and SW707) inhibit miR-210 induced apoptosis (Fig. 3a, b). With regard to Mcl-1, CRC cell lines were transduced with an Mcl-1 AdV and transfected with miR-210 oligonucleotides. Overexpression of Mcl-1 significantly reduced miR-210 mediated apoptosis in SW480 and SW707 cells, however no effect on apoptosis rate in HCT116 cells was observed (Fig. 3c, d).

\section{Inhibition of ROS partially protects cells from miR-210 induced cell death}

MiR-210 overexpression has been associated with an impairment of mitochondrial function in various cellular contexts [37, 39, 40]. These effects have mainly been associated with miR-210 mediated regulation of the Fe-S cluster scaffold protein ISCU [39-42]. Thus, we examined the effects of miR-210 overexpression on ROS generation and ISCU expression in our cellular system. Importantly, 

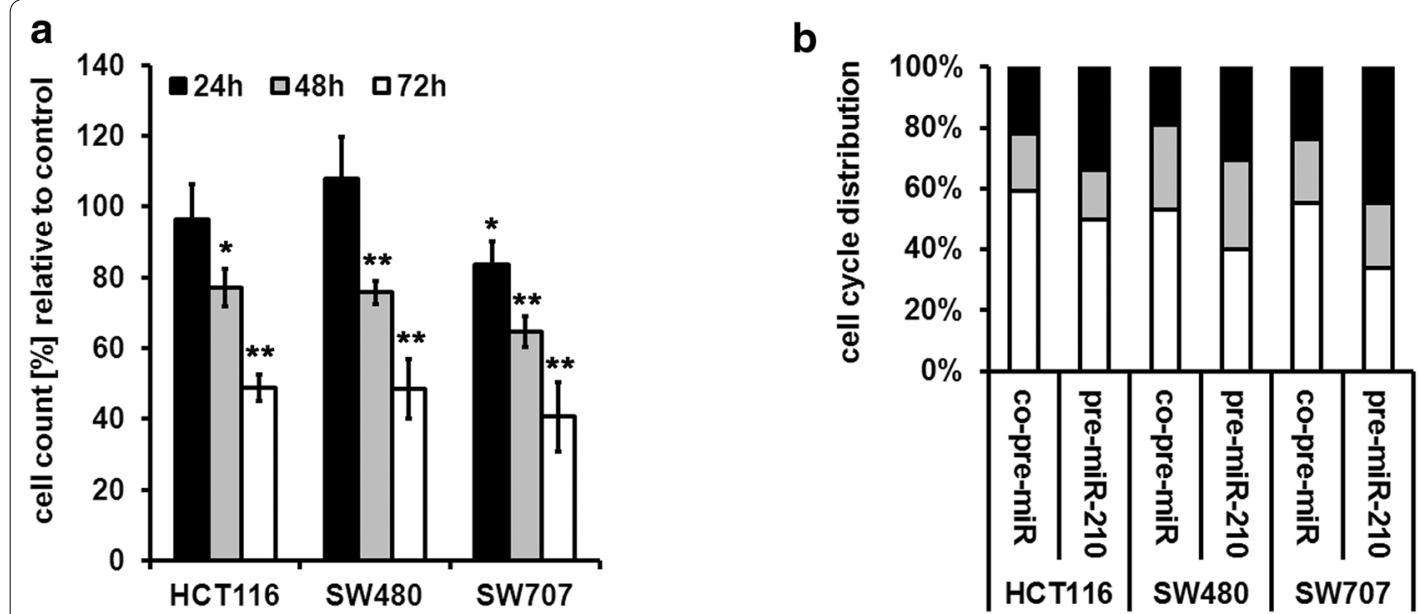

口G1 phase

口S phase

-G2/M phase
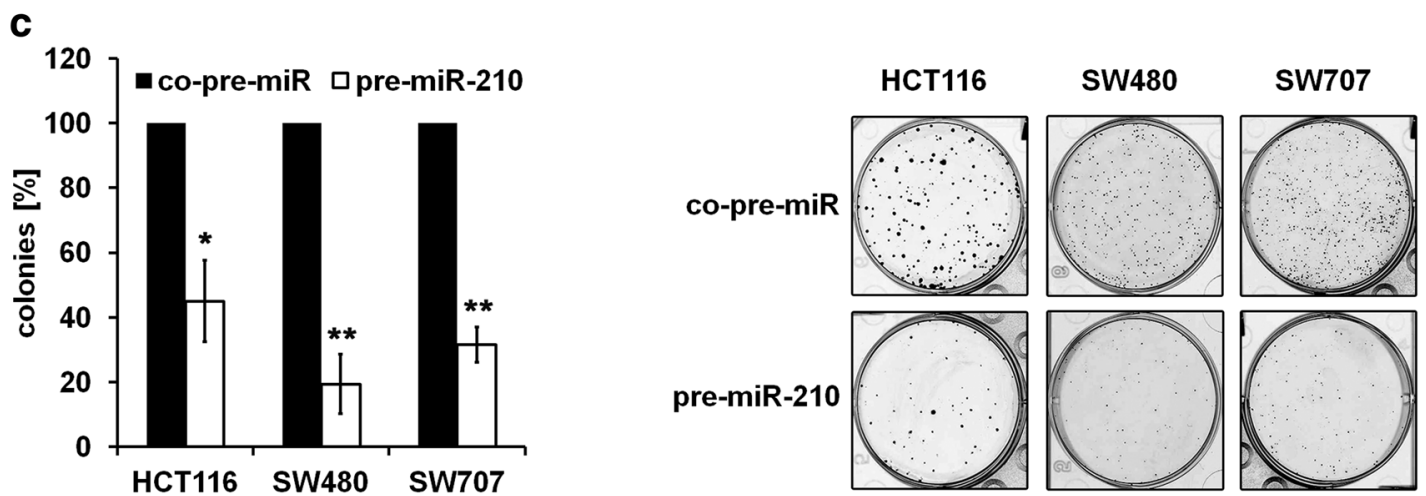

Fig. 1 Overexpression of miR-210 inhibits cell growth. a Proliferation assay of CRC cell lines 24,48 and $72 \mathrm{~h}$ after transfection with pre-miR-210 and a control miRNA, respectively. Cells were trypsinized and counted (mean $\pm \mathrm{SEM} ; \mathrm{n}=3 ;{ }^{*} p<0.05 ;{ }^{* *} p<0.01$; student's $\mathrm{t}$ test). b Measurement of cell cycle distribution was performed $48 \mathrm{~h}$ after transfection of pre-miR-210 and a control miRNA, respectively. Cells were stained with PI and the DNA content was measured by FACS analysis. Data represent the mean of three independent experiments. c Pre-miR-210 and control miRNA transfected CRC cells were seeded into 6-well-plates ( 500 cells/well) $72 \mathrm{~h}$ post transfection and cultured for 7 days. The colonies were subsequently stained with crystal violet and counted (left panel; mean $\pm \mathrm{SEM} ; \mathrm{n}=3$; ${ }^{*} p<0.05 ;{ }^{* *} p<0.01$; student's t-test). A representative picture is shown (right panel)

overexpression of miR-210 resulted in a substantial increase in ROS generation (Fig. 4a). Further, we observed a distinct decrease in ISCU expression upon transfection of miR-210 oligonucleotides (Fig. 4b). Moreover, siRNA mediated downregulation of ISCU increased cellular ROS generation and induced apoptosis (Additional file 3: Figure S3a, b). However, overexpression of ISCU did not counteract miR-210 mediated ROS and apoptosis induction (Additional file 3: Figure S3c, d). Since ROS is known to induce apoptosis via the activation of Caspase 2 [43, 44], we investigated its processing dependent on miR-210 expression. In fact, overexpression of miR-210 resulted in Caspase 2 cleavage (Fig. 4c). Additionally, as Caspase 3 is able to activate Caspase $2[45,46]$, we further wanted to exclude that the enhanced processing of Caspase 2 was exclusively mediated through a positive feed-back-loop resulting from an increased activation of Caspase 3. To this end, we transfected MCF-7 breast cancer cells, lacking Caspase 3 expression [47], with pre-miR-210 and control oligonucleotides, respectively. Immunoblot analysis revealed that overexpression of miR-210 provoked Caspase 2 processing in MCF-7 cells as well (Fig. $4 \mathrm{~d}$ ), thereby confirming that processing of Caspase 2 was independent of the activation of Caspase 3 within this context.

To further elucidate the role of ROS in miR-210 mediated apoptosis, cells were treated with the ROS scavenger $\mathrm{N}$-acetylcysteine (NAC), which resulted in a decrease in miR-210 induced ROS generation (Fig. 5a). Although inhibition of ROS generation did neither affect expression levels of Bim, nor impair the cleavage of Caspase 2 (Fig. 5b, c), NAC treatment led to a considerable decrease in miR-210 mediated cell death (Fig. 5d) and to a diminished cleavage of Caspase 3 (Fig. 5e), thereby suggesting a role of ROS generation in miR-210 mediated cell death. 


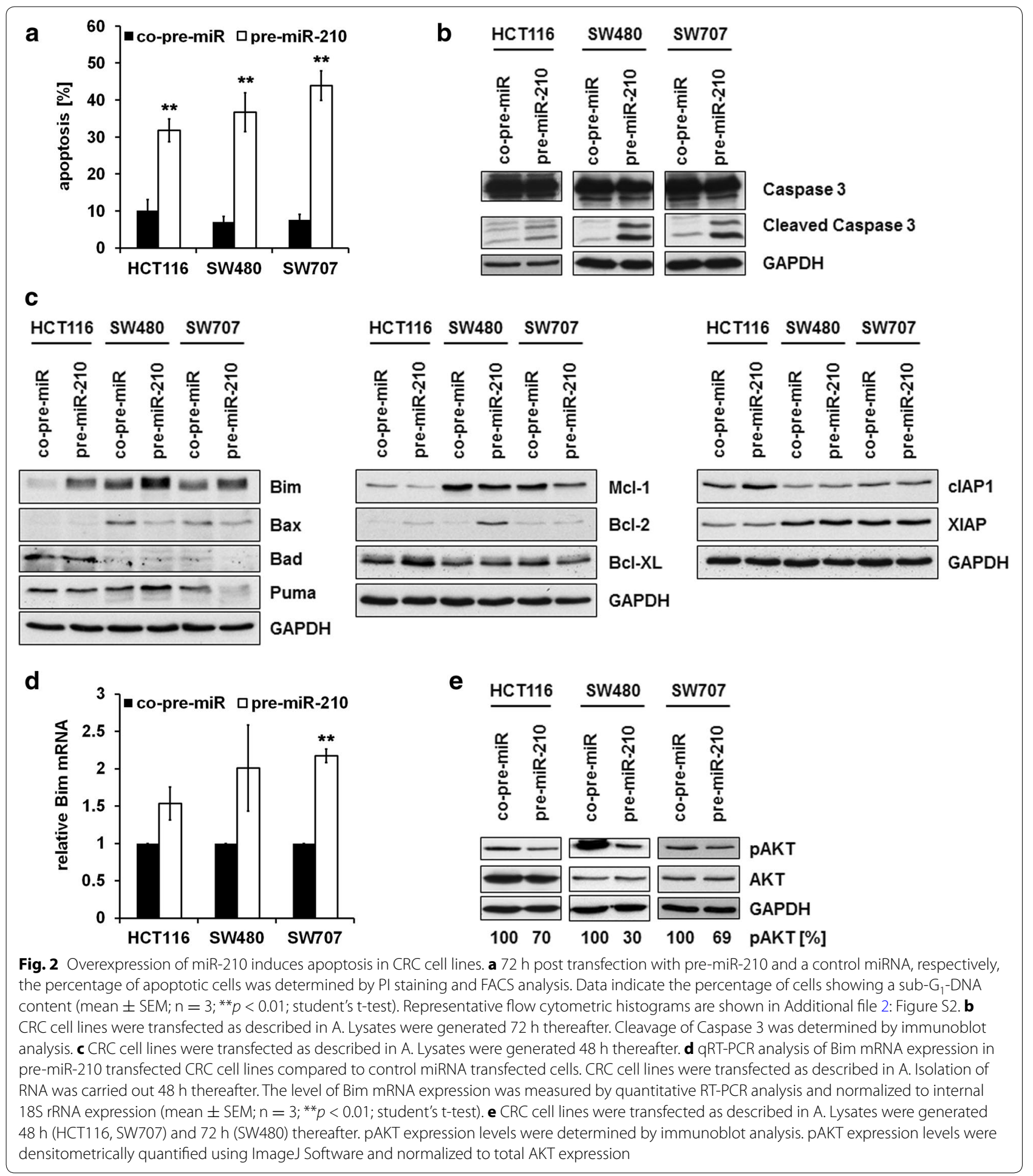

\section{Discussion}

Altered expression of miR-210 can modulate either apoptosis resistance or sensitivity depending on the cellular context [10, 21, 32-37]. MiR-210 has been shown to be upregulated in CRC compared to normal tissue [17].
Further, high expression levels of miR-210 both in tumor tissue and serum of CRC patients correlate with a poor prognosis $[17,18]$. Within this study we sought to explore the functional effects of an increased miR-210 expression in CRC. 

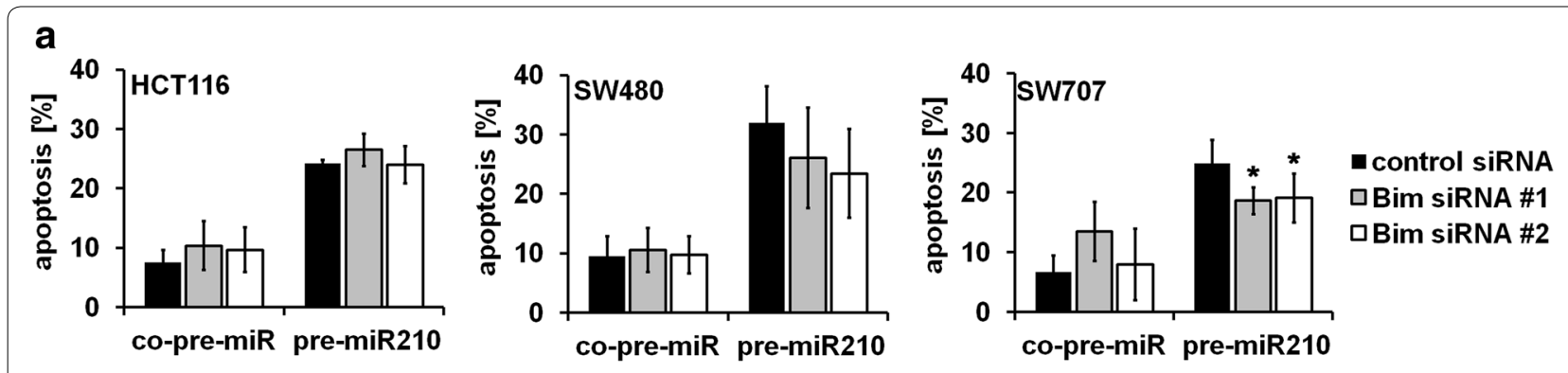

b

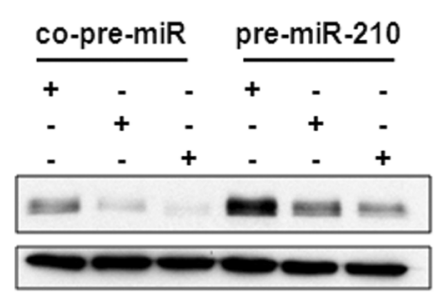

HCT116
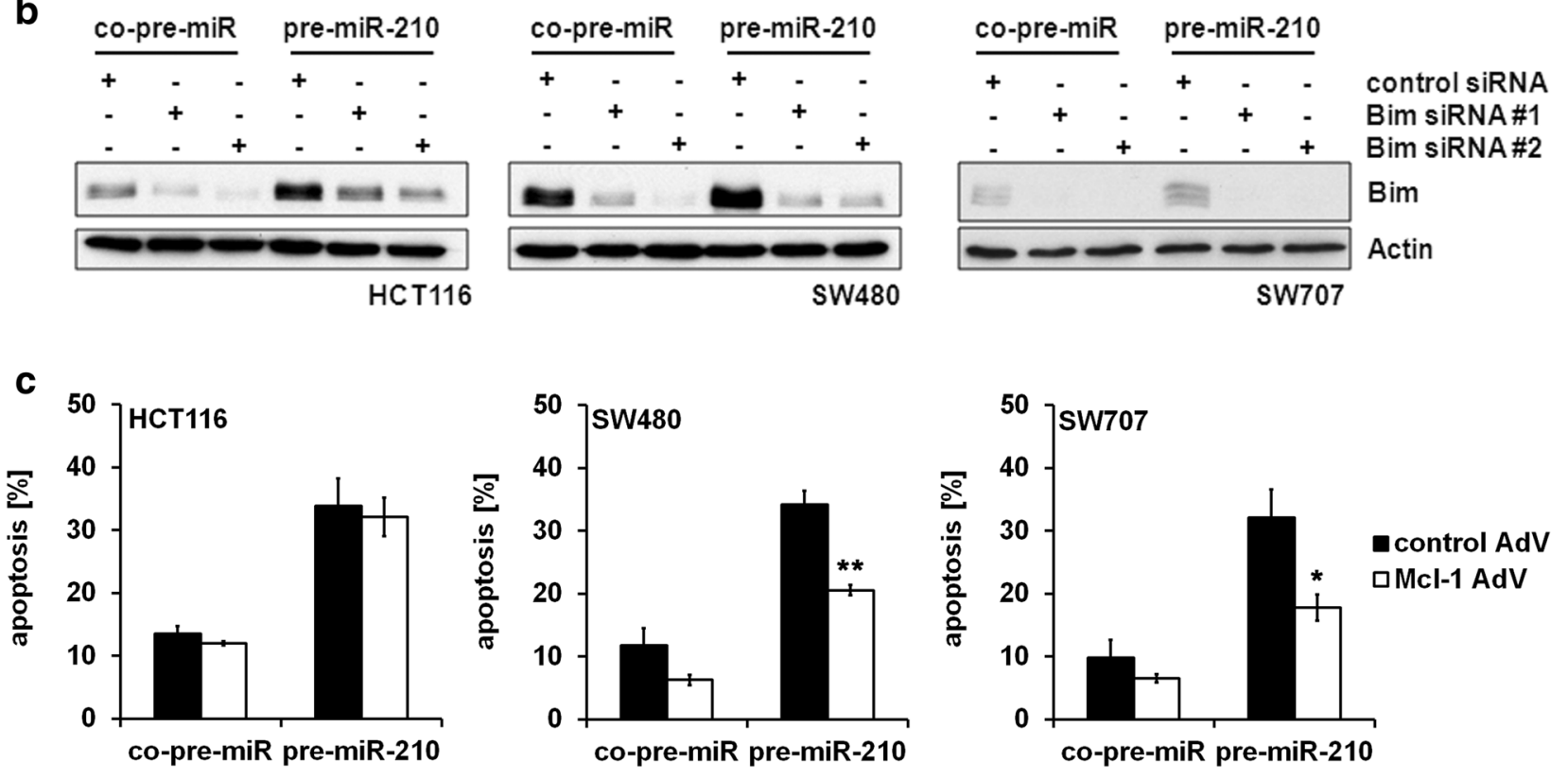

d

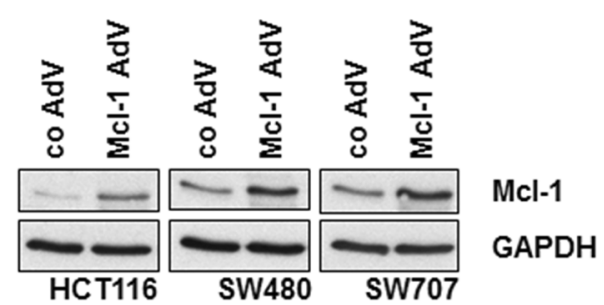

Fig. 3 Downregulation of Bim and upregulation of Mcl-1 inhibit miR-210-mediated apoptosis. a CRC cell lines were transfected with pre-miR-210 and a control miRNA, respectively. Concomitantly, they were transfected either with two different Bim-specific siRNAs or a control siRNA. $72 \mathrm{~h}$ post transfection, the percentage of apoptotic cells was determined by PI staining and FACS analysis. Data indicate the percentage of cells showing a sub-G $\mathrm{G}_{1}$-DNA content (mean $\pm \mathrm{SEM} ; \mathrm{n}=3 ;{ }^{*} p<0.05$; student's t-test). $\mathbf{b}$ CRC cells were transfected as described in A. Lysates were generated $72 \mathrm{~h}$ thereafter. The successful knockdown of Bim was monitored by immunoblot analysis. $\mathbf{c} C R C$ cell lines were transduced with Mcl-1 AdV and a control $A d V$, respectively. $24 \mathrm{~h}$ thereafter, cells were transfected with pre-miR-210 or a control miRNA. The percentage of apoptotic cells was determined $72 \mathrm{~h}$ after transfection by PI staining and FACS analysis. Data indicate the percentage of cells showing a sub- $\mathrm{G}_{1}-\mathrm{DNA}$ content ( $m$ ean $\pm \mathrm{SEM} ; \mathrm{n}=3$; ${ }^{*} p<0.05 ;{ }^{* *} p<0.01$; student's t-test). $\mathbf{d}$ CRC cell lines were transduced with Mcl-1 AdV and a control AdV, respectively. Lysates were generated $72 \mathrm{~h}$ thereafter

Our results indicate that miR-210 functions in an antitumorigenic manner by decreasing proliferation accompanied by an increased amount of cells in the G2/M phase of the cell cycle. This is in accordance with previous studies showing an accumulation of cells in the G2 phase in various tumor entities upon miR-210 overexpression $[35,36,48]$. Moreover it has been shown that miR-210 overexpression induces senescence in fibroblasts [49] and 


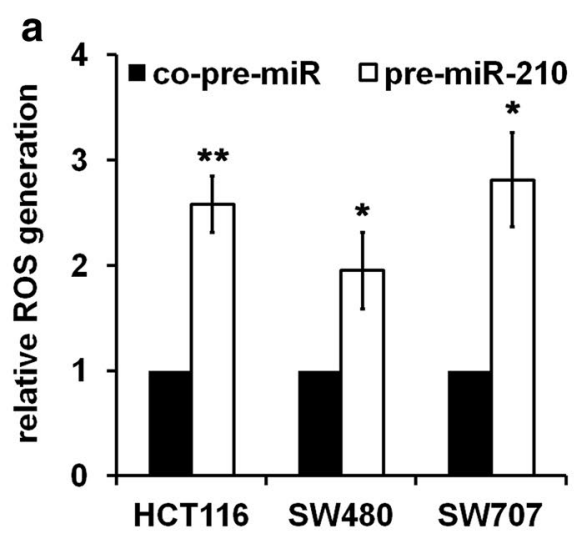

C

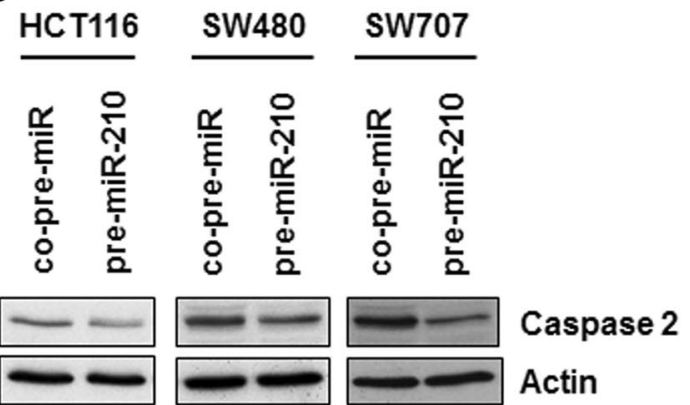

b

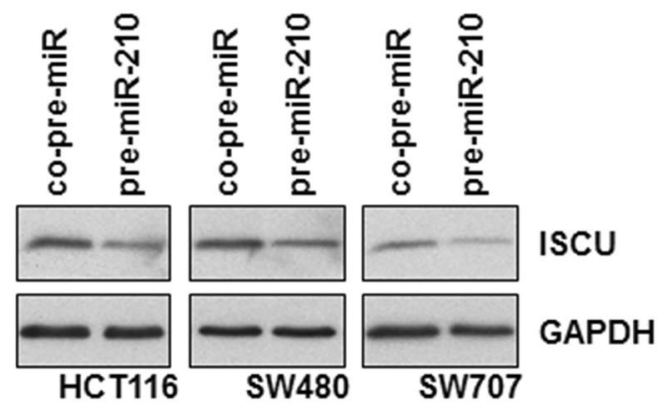

d

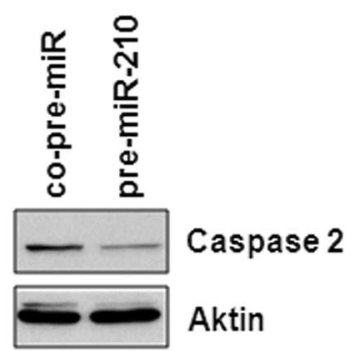

Fig. 4 Overexpression of miR-210 induces ROS generation. a Measurement of ROS generation was performed $48 \mathrm{~h}$ after transfection of premiR-210 and a control miRNA, respectively (mean \pm SEM; $n=3 ;{ }^{*} p<0.05 ; *^{* *} p<0.01$; student's t-test). $\mathbf{b}$ CRC cell lines were transfected as described in A. Lysates were generated $48 \mathrm{~h}$ thereafter. ISCU expression was analyzed by immunoblot analysis. $\mathbf{c} C R C$ cell lines were transfected as described in A. Lysates were generated $48 \mathrm{~h}$ thereafter. Caspase 2 processing was analyzed by immunoblot analysis. $\mathbf{d}$ MCF-7 breast cancer cells were transfected as described in A. Lysates were generated $72 \mathrm{~h}$ thereafter. Caspase 2 processing was analyzed by immunoblot analysis

reduces tumor growth and proliferation in hepatocellular xenografts [33]. Several direct and indirect targets of miR-210 might account for this effect. Zheng et al. previously demonstrated that overexpression of miR210 blocks the expression of CyclinD1 and CyclinD2 via $\mathrm{SHH} / \mathrm{Gli1}$ signaling [50]. Additionally, the miR-210 target E2F3 $[22,36]$ plays an important role in regulation of proliferation [51]. He et al. further proposed Plk1, CyclinF, Bub1B, CDC25B and Fam83D to be involved in miR210-mediated cell cycle arrest [48]. In addition to the direct targets of miR-210, proliferation arrest might be induced by an increased ROS generation. Several targets are known that are involved in cell cycle regulation and are regulated by ROS. The observed accumulation of cells in G2 phase might therefore be caused by the regulation of the oxidative state of $\mathrm{Cdc} 25 \mathrm{C}$. This phosphatase which activates cyclinB/cdk1 complexes, might be repressed by elevated ROS levels by inducing an inhibitory disulfide bond [52]. Besides a direct regulation of cellular proliferation, elevated amounts of ROS might contribute to the observed effects via activation of FOXOs. These transcription factors regulate the transactivation of a series of genes involved in cell cycle control [53]. Activation of the FOXO transcription factors might occur upon increased ROS levels by MST1, which is activated upon nuclear DNA damage [54] or by inhibition of the AKT kinase, which negatively regulates FOXOs [55]. Interestingly, we observed a decrease in phosphorylated AKT upon miR210 overexpression. Similarly, Luo et al. recently demonstrated a ROS-dependent inactivation of AKT signaling accompanied with an increased activity of FOXO3a in colorectal cancer cells [56].

An increased generation of ROS upon miR-210 upregulation has so far been observed in colorectal carcinoma [42], in adipose-derived stem cells [57] and fibroblasts [49]. Furthermore, it has been shown that an elevated expression of miR-210 reduces oxygen consumption and upregulates glycolysis in various tumor entities [39, 40, $42,58]$. Within this context, it has been observed, that the activity of mitochondrial complex I $[39,40]$ and II [37] is impaired, resulting in an increased formation of ROS [54]. These effects have been proposed to be based on miR-210 mediated regulation of the Fe-S cluster scaffold protein ISCU [39-42], SDHD [37], a subunit of the 

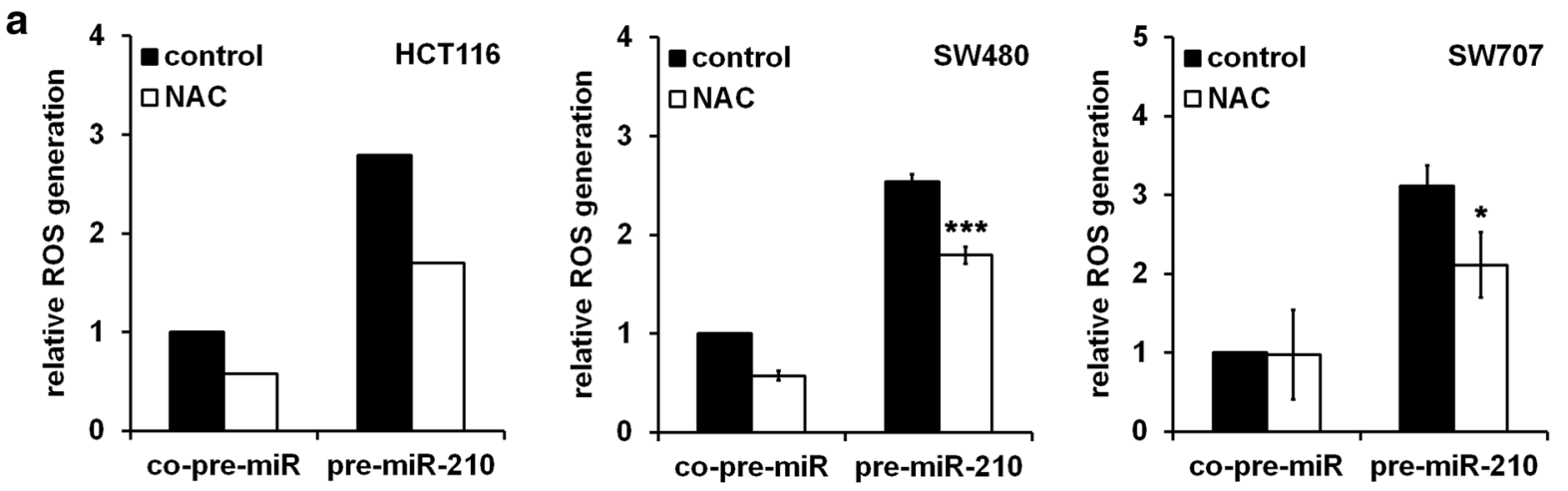

b
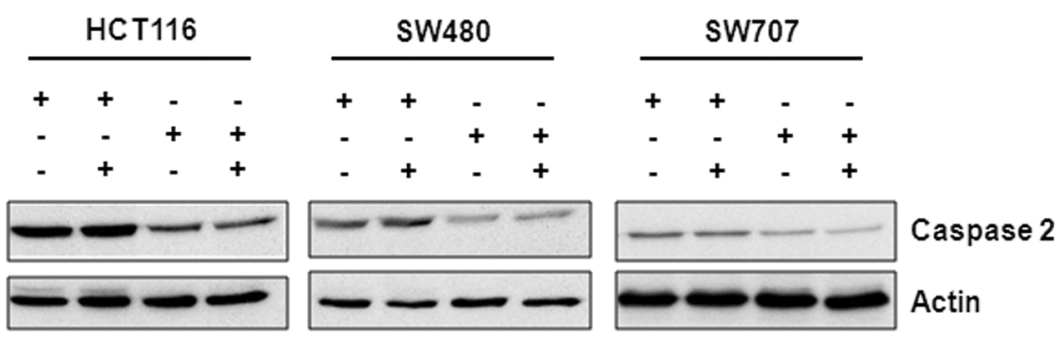

C
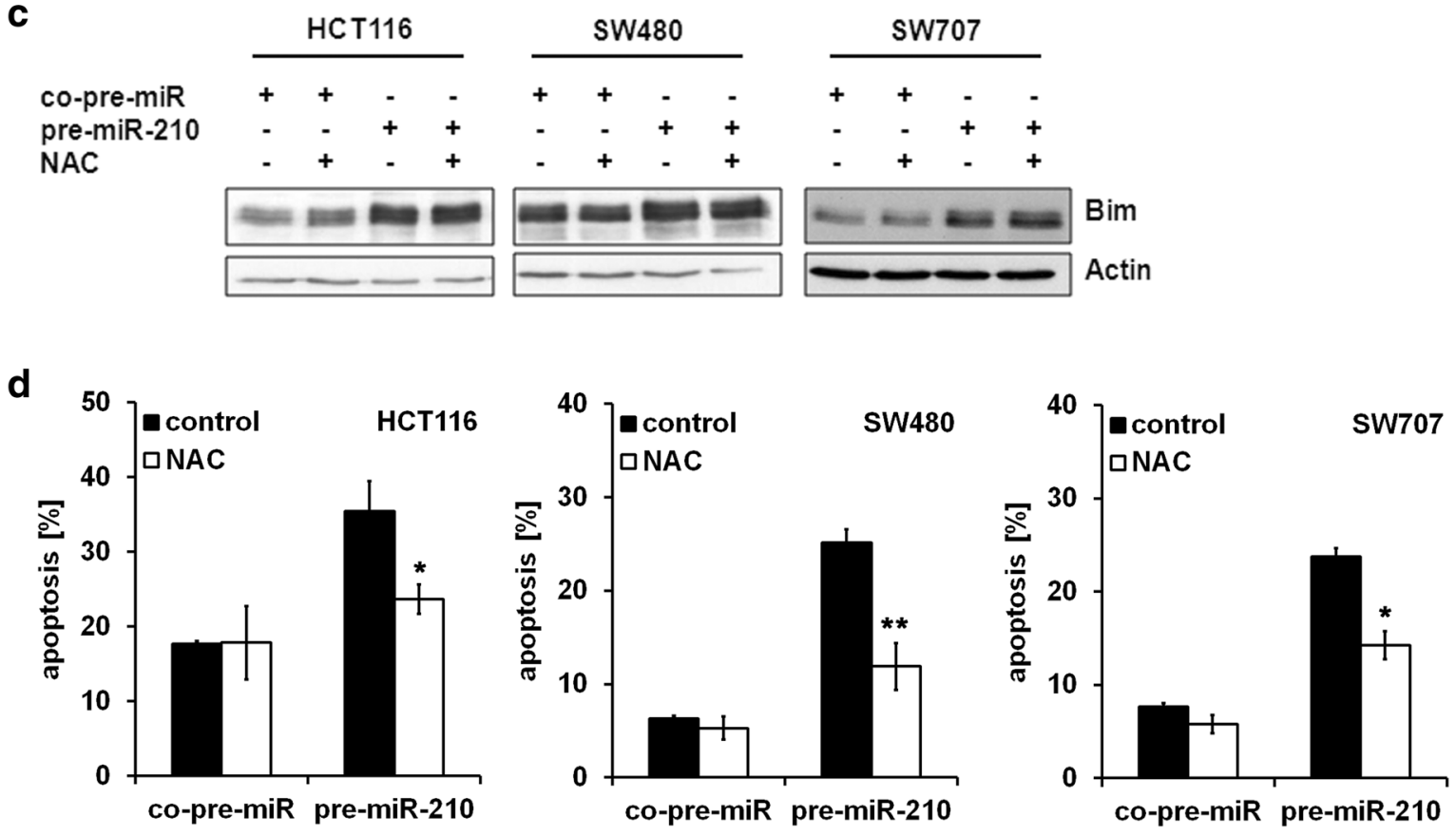

e
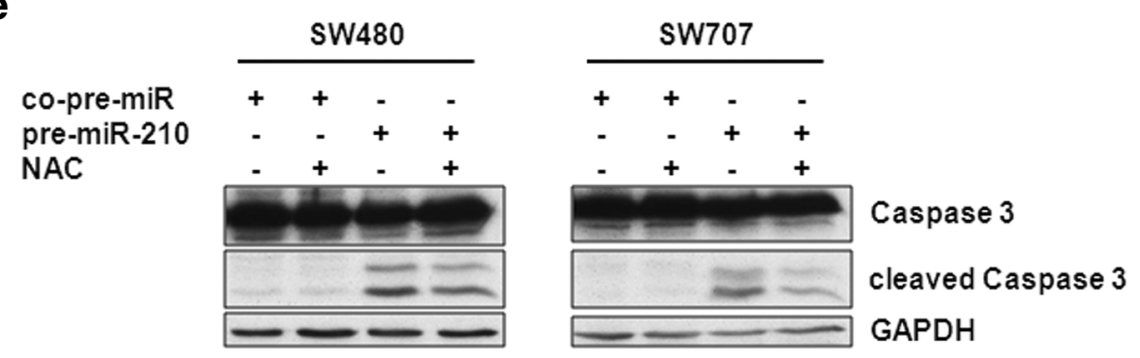
(See figure on previous page.)

Fig. 5 Inhibition of ROS generation affects miR-210 induced cell death. CRC cells were transfected with pre-miR-210 and a control miRNA, respectively. $24 \mathrm{~h}$ post transfection, cells were treated with NAC. a Measurement of ROS generation was performed $24 \mathrm{~h}$ post NAC treatment ( $30 \mathrm{mM}$ ) (HCT116: $\mathrm{n}=1$; SW480, SW707: $\mathrm{n}=3$; mean $\pm \mathrm{SEM} ;{ }^{* * *} p<0.001 ;{ }^{*} p<0.05$; student's t-test). b Lysates were generated $48 \mathrm{~h}$ post NAC treatment $(10 \mathrm{mM})$. Processing of Caspase 2 was analyzed by immunoblot analysis. $\mathbf{c}$ Lysates were generated $48 \mathrm{~h}$ post NAC treatment (10 mM). Bim expression levels were determined by immunoblot analysis. d The percentage of apoptotic cells was determined $48 \mathrm{~h}$ post NAC treatment (30 mM) by PI staining and FACS analysis. Data indicate the percentage of cells showing a sub-G - DNA content (mean $\pm \mathrm{SEM} ; \mathrm{n}=3 ;{ }^{*} p<0.05 ;{ }^{* *} p<0.01$; student's t-test). e Lysates were generated $48 \mathrm{~h}$ post NAC treatment $(10 \mathrm{mM})$. Cleavage of Caspase 3 was determined by immunoblot analysis

succinate dehydrogenase complex, COX10 [42], a subunit of cytochrome c oxidase, and NDUFA4 [37], a subunit of the NADH dehydrogenase 1 alpha subcomplex. In line with these observations we could also detect a decreased expression of ISCU and NDUFA4 (data not shown) upon miR-210 overexpression. Whereas siRNA-mediated downregulation of ISCU increased ROS generation and induced apoptosis, siRNA-mediated downregulation of NDUFA4 did neither alter ROS generation nor apoptosis rates (data not shown). However, ectopic overexpression of ISCU did not counteract miR-210 mediated apoptosis and ROS generation. Therefore, it might by very likely, that ISCU is only one of several miR-210 targets regulating ROS generation. This is also evidenced by the effects of ISCU downregulation, since the reduced expression of ISCU did not completely reach the extent of miR-210 overexpression with regard to ROS generation and apoptosis induction.

Although there are several studies investigating the effect of a modulated miR-210 expression on apoptosis, the underlying molecular mechanisms are far from clear. Within this study we provide evidence, that an increased ROS generation induced by miR-210 overexpression contributes to the apoptotic phenotype. One of the most common pathways contributing to ROS-induced apoptosis is the ASK1 signaling cascade. Induction of ROS results in the oxidation of the inhibitory protein thioredoxin. Subsequently ASK1 and the downstream stress kinases JNK and p38 get activated, whereas the latter are able to induce cell death [59].

Besides the ASK1/JNK/p38 signaling axis, the transcription factor FOXO3 might contribute to the apoptotic effects upon ROS generation by transactivation of its target genes Bim, Bcl-6 and Noxa [54]. Within this context, FOXO3 might be activated by MST1 or inhibited by the AKT kinase [54, 55]. Accordingly, it was recently demonstrated that ROS-dependent inactivation of the AKT signaling pathway was accompanied by an increase in Bim expression levels [56]. Indeed, we detected an increase of Bim expression levels upon miR-210 overexpression, which was at least partially due to transcriptional regulation. Besides, ROS-induced ER stress and subsequent activation of the transcription factor $\mathrm{CHOP}$ might also contribute to the elevated Bim expression [38, 60]. However, siRNA-mediated downregulation of Bim did not (HCT116) or only slightly (SW480 and SW707) diminish miR-210-mediated apoptosis, pointing to a different mechanism triggering miR-210-mediated apoptosis. Furthermore, inhibition of ROS generation using NAC did not alter Bim expression levels, rendering a ROS-dependent regulation of Bim rather unlikely.

Interestingly, we observed a miR-210 mediated upregulation of the anti-apoptotic Bcl-2 protein in HCT116 and SW480 cells. So far it has been reported, that Bcl-2 overexpression can either inhibit or increase ROS induced apoptosis [61-63]. In this regard, we observed, that ectopic overexpression of Bcl-2 significantly reduced miR-210 mediated apoptosis (data not shown). Within this context it is tempting to speculate whether an increased expression of miR-210 sensitizes cancer cells to Bcl-2 inhibitors.

Within this study we could further demonstrate, that overexpression of miR-210 results in an increased processing of Caspase 2. Induction of ROS has been shown to induce activation of Caspase $2[43,44]$ in a both p53-dependent and -independent manner $[64,65]$ which might further result in apoptosis by Caspase 2-mediated cleavage of Bid or by directly inducing the release of Cyt c, AIF and SMAC from the mitochondria [66]. However inhibition of ROS generation did not alter Caspase 2 processing nor did Caspase 2 downregulation inhibit miR210 induced cell death (data not shown).

The functional consequences of an increased miR-210 expression in cancer patients are so far unknown. It has been shown, that elevated miR-210 expression levels might either be beneficial [29-31] or be accompanied by a poor prognosis $[15,17,18,23-27]$. However, it is still unclear whether the latter is directly caused by increased expression levels of miR-210. Since hypoxia is one of the main factors contributing to a poor prognosis of cancer patients [67], elevated miR-210 expression levels, which are mainly regulated by HIF transcription factors $[25,68$, 69], might only be a bystander effect instead of directly influencing patients' outcome. Therefore, the regulation of apoptosis by miR-210 might be of great biological relevance in CRC and warrants further investigation. 


\section{Conclusions}

Our experiments identify miR-210 as an inductor of apoptosis in CRC cells. Our results further identify miR210-mediated increase in ROS generation as a key driver of miR-210-induced apoptosis.

\section{Methods \\ Materials}

$\mathrm{N}$-acetylcysteine was obtained from Sigma-Aldrich (St. Louis, MO, USA, A9165). The antibodies were obtained as follows: anti-actin (Chemicon, Billerica, MA, USA, 1501); anti-AKT (Cell Signaling, Danvers, MA, USA, 9272); anti-Bad (Santa Cruz, Dallas, TX, USA, sc-7869); anti-Bax (Santa Cruz, sc-493); anti-Bcl-2 (Santa Cruz; sc-509); anti-Bcl-XL (Cell Signaling, 2764); anti-Bim (Cell Signaling, 2933); anti-Caspase 2 (Cell Signaling, 2224); anti-Caspase 3 (Imgenex, San Diego, CA, USA, IMG144A); anti-cIAP1 (R\&D Systems, Minneapolis, MN, USA, AF8181); anti-GAPDH (Santa Cruz, sc-32233); anti-ISCU (Santa Cruz; sc-373694); anti-Mcl-1 (Santa Cruz, sc-819); anti-pAKT (S472/473) (Cell Signaling, 4058); anti-Puma (Cell Signaling, 4976); anti-XIAP (Cell Signaling, 2045).

\section{Cell culture}

The human colorectal cancer cell lines HCT116, SW480 and SW707 as well as the human breast cancer cell line MCF-7 were purchased from the American Type Culture Collection (ATCC, USA), maintained in RPMI medium (Life Technologies, Darmstadt, Germany) supplemented with $10 \%$ fetal calf serum (Sigma-Aldrich), $1 \mathrm{mM}$ glutamine, $25 \mathrm{mM}$ glucose and $1 \%$ penicillin/streptomycin (Life Technologies) and cultured at $37{ }^{\circ} \mathrm{C}$ in a $5 \% \mathrm{CO}_{2}$ atmosphere. Cell lines were regularly tested for the presence of contamination using multiplex cell contamination test [70] and authenticated by SNP profiling [71].

\section{Proliferation and clonogenicity assay}

For the assessment of proliferation, cells were seeded into 6-cm culture dishes and counted after 24, 48 and $72 \mathrm{~h}$ using the trypan blue exclusion assay. For clonogenicity assays, 500 cells were seeded into 6-well culture dishes and incubated for 7 days prior to crystal violet staining and colony counting.

\section{FACS analysis}

For analysis of cell cycle distribution and cell death, colorectal cancer cell lines were stained with propidium iodide (PI) as described previously [72].

For measurement of reactive oxygen species (ROS), colorectal cancer cells were seeded in 6- $\mathrm{cm}$ plates and transfected as indicated. Cells were incubated with the fluorescent H2DCF-DA (2,7-dichlorodihydrofluorescein diacetate; $5 \mu \mathrm{M}$; Biozol, Eching, Germany) for $30 \mathrm{~min}$ at $37^{\circ} \mathrm{C}$.

Cells were subjected to flow cytometry analysis using a Becton-Dickinson FACScalibur cytometer and Cell Quest Software.

\section{Transfections}

Colorectal cancer cells were transiently transfected with siRNA using Lipofectamine 2000 (Life Technologies). Pre-miR-210 (miR precursor; PM10516) and co-pre-miR (control; AM17110) oligonucleotides were obtained from Life Technologies and used in a concentration of $50 \mathrm{nM}$. Bim siRNA \# 1 and \#2 were obtained from Thermo Scientific (Waltham, MA, USA, \#D-004383-18, \#D-004383-17) and used in a concentration of $25 \mathrm{nM}$. ISCU siRNA was obtained from Life Technologies (\#s23908) and used in a concentration of $5 \mathrm{nM}$. A non-specific siRNA served as a control (Thermo Scientific, \#D-001810-01).

The pcDNA3-ISCU plasmid was generated by PCR from the clone pENTR221-ISCU, provided by the ORFeome Collaboration (Genomics and Proteomics Core Facility, DKFZ, Heidelberg, Germany) using the following forward (F) and reverse (R) primers containing BamHI and XhoI restrictions sites: 5' $5^{\prime}$ ATGCATGCATGG ATCCACCATGGCGGCGGCTGGGGCT $-3^{\prime}(\mathrm{F})$ and 5' - ATGCATGCATCTCGAGCAAGAAAGCTGGGTCC AATTTC $-3^{\prime}(\mathrm{R})$. The PCR products were digested with $B a m \mathrm{HI}$ and $\mathrm{XhoI}$ and cloned into the correspondent sites of pcDNA3-Flag. For the generation of stable transfectants, complete medium containing Geneticin ${ }^{\circledR}$ (G418, Invitrogen) at a concentration of $1.5 \mathrm{mg} / \mathrm{mL}$ was used to select stably transfected cells.

\section{Adenoviral transduction}

Mcl-1-AdV was produced as described previously [73]. The control AdV consists of the empty AdV5 backbone and was kindly provided by Stefan Herzig (DKFZ, Heidelberg, Germany). CRC cells were incubated with recombinant AdVs directly after seeding using a multiplicity of infection of 10 (HCT116) or 200 (SW480, SW707).

\section{Immunoblot analysis}

Cellular lysate generation and immunoblot analysis were performed as described previously [72]. Densitometric analyses were performed using ImageJ software (National Institutes of Health, Bethesda, MD, USA, http://www.rsb. info.nih.gov/ij/).

\section{Quantitative PCR analysis}

Quantitative real-time PCR was performed as described previously [73]. Following primer pairs were used: Bim: 5'-CAACACAAACCCCAAGTCCT-3' (forward), 5'-TC TTGGGCGATCCATATCTC-3' (reverse); 18S: 5'-CATG 


\section{GCCGTTCTTAGTTGGT-3' (forward), 5' ATGCCAGAG TCTCGTTCGTT-3' (reverse).}

For measurement of miRNA expression, total RNA was isolated using the miRNeasy Mini Kit (Qiagen, Hilden Germany). Mature miRNAs were reversely transcribed using TaqMan ${ }^{\circledR}$ MicroRNA reverse transcription kit (Thermo Scientific) and TaqMan ${ }^{\circledR}$ MicroRNA Arrays (Thermo Scientific). Quantitative PCR analysis was performed using the TaqMan ${ }^{\circledR}$ Universal PCR Master Mix (Thermo Scientific) and a 7300 Real-Time PCR System (Applied Biosystems, Foster City, CA, USA). All steps were carried out according to the to the manufacturer's protocols.

\section{Statistical methods}

Significant differences were identified using the unpaired 2 -sided Student $t$ test. Throughout, $p$ values $<0.05$ were considered significant and are indicated as follows: " $p<0.05,{ }^{* * *} p<0.01, * * * p<0.001$.

\section{Additional files}

Additional file 1: Figure S1. CRC cell lines were transfected with premiR-210 and a control miRNA, respectively. $48 \mathrm{~h}$ thereafter, total RNA including miRNA was isolated. Expression of miR-210 was measured by qRT-PCR analysis and normalized to internal U47 snoRNA expression (mean \pm SEM; $n=3$ ).

Additional file 2: Figure S2. Representative flow cytometric histograms of CRC cell lines $72 \mathrm{~h}$ post transfection with pre-miR-210 and a control miRNA, respectively. Cells were stained with by PI staining and subjected to FACS analysis.

Additional file 3: Figure S3. a CRC cell lines were transfected with an ISCU specific siRNA and a control siRNA, respectively. ROS generation was measured $48 \mathrm{~h}$ after transfection (left panel; mean $\pm \mathrm{SEM} ; n=3 ;{ }^{*} p<0.05$; ${ }^{* *} p<0.01$; student's t-test). Successful knockdown of ISCU was monitored by immunoblot analysis. Lysates were generated $48 \mathrm{~h}$ after transfection (right panel). b Cells were transfected as described in a. The percentage of apoptotic cells was determined $72 \mathrm{~h}$ post transfection by PI staining and FACS analysis. Data indicate the percentage of cells showing a sub-G1DNA content (mean $\pm \mathrm{SEM} ; \mathrm{n}=3 ;{ }^{* *} p<0.01$; student's t-test). c $C R C$ cell lines stably overexpressing ISCU or an empty vector control (neo) were transfected with pre-miR-210 and a control miRNA, respectively. Measurement of ROS generation was performed $48 \mathrm{~h}$ thereafter (left panel; mean $\pm \mathrm{SEM} ; n=3$ ). Successful overexpression of ISCU-Flag was monitored by immunoblot analysis. $\mathbf{d}$ Cells were transfected as described in c. The percentage of apoptotic cells was determined by PI staining and FACS analysis (mean $\pm S E M ; n=3$ ).

\section{Abbreviations}

AdV: adenovirus; CRC: colorectal cancer; NAC: N-acetylcysteine; ROS: reactive oxygen species.

\section{Authors' contributions}

KET was involved in acquisition of data, in study conception and design, in analysis and interpretation of data, and in drafting the manuscript. AF participated in study conception and design, in analysis and interpretation of data. TS, JR, and SS were involved in acquisition of data. SMG was involved in analysis and interpretation of data. WR participated in study conception and design, in analysis and interpretation of data, and in drafting the manuscript. All authors read and approved the final manuscript.

\section{Author details}

${ }^{1}$ Molecular Tumor-Pathology, German Cancer Research Center (DKFZ), 69120 Heidelberg, Germany. ${ }^{2}$ Institute of Pathology, University of Heidelberg, 69120 Heidelberg, Germany. ${ }^{3}$ Institute of Pathology, University Medical Center Mainz, Langenbeckstraße 1, 55131 Mainz, Germany. ${ }^{4}$ Present Address: Department of Cancer Biology, Dana-Farber Cancer Institute, Boston, MA 02215, USA. ${ }^{5}$ Department of Genetics, Harvard Medical School, Boston, MA 02215, USA.

\section{Acknowledgements}

We thank Stefan Herzig (DKFZ, Heidelberg) for kindly providing recombinant adenoviruses, and Martina Keith for excellent technical assistance. We further thank all laboratory members for helpful suggestions and discussions. This study was supported by the German Research Foundation (DFG; \#RO2270/6-1).

\section{Competing interests}

The authors declare that they have no competing interests.

Received: 26 June 2015 Accepted: 2 June 2016

Published online: 10 June 2016

\section{References}

1. Jemal A, Bray F, Center MM, Ferlay J, Ward E, Forman D. Global cancer statistics. CA Cancer J Clin. 2011;61(2):69-90.

2. Bartel DP. MicroRNAs: target recognition and regulatory functions. Cell. 2009;136(2):215-33.

3. Ventura A, Jacks T. MicroRNAs and cancer: short RNAs go a long way. Cell. 2009;136(4):586-91.

4. Winter J, Diederichs S. MicroRNA biogenesis and cancer. Methods Mol Biol. 2011;676:3-22.

5. Lee RC, Feinbaum RL, Ambros V. The C. elegans heterochronic gene lin-4 encodes small RNAs with antisense complementarity to lin-14. Cell. 1993;75(5):843-54.

6. Hogan NM, Joyce MR, Kerin MJ. MicroRNA expression in colorectal cancer Cancer Biomark. 2012:11(6):239-43.

7. Vosa U, Vooder T, Kolde R, Vilo J, Metspalu A, Annilo T. Meta-analysis of microRNA expression in lung cancer. Int J Cancer. 2013;132(12):2884-93.

8. Guan P, Yin Z, Li X, Wu W, Zhou B. Meta-analysis of human lung cancer microRNA expression profiling studies comparing cancer tissues with normal tissues. J Exp Clin Cancer Res. 2012;31:54.

9. Miko E, Czimmerer Z, Csanky E, Boros G, Buslig J, Dezso B, et al. Differentially expressed microRNAs in small cell lung cancer. Exp Lung Res. 2009;35(8):646-64.

10. Redova M, Poprach A, Besse A, lliev R, Nekvindova J, Lakomy R, et al. MiR210 expression in tumor tissue and in vitro effects of its silencing in renal cell carcinoma. Tumour Biol. 2013;34(1):481-91.

11. Osanto S, Qin Y, Buermans HP, Berkers J, Lerut E, Goeman JJ, et al. Genome-wide microRNA expression analysis of clear cell renal cell carcinoma by next generation deep sequencing. PLoS One. 2012;7(6):e38298.

12. Juan D, Alexe G, Antes T, Liu H, Madabhushi A, Delisi C, et al. Identification of a microRNA panel for clear-cell kidney cancer. Urology. 2010;75(4):835-41.

13. Munari E, Marchionni L, Chitre A, Hayashi M, Martignoni G, Brunelli M, et al. Clear cell papillary renal cell carcinoma: micro-RNA expression profiling and comparison with clear cell renal cell carcinoma and papillary renal cell carcinoma. Hum Pathol. 2014;45(6):1130-8.

14. Papaconstantinou IG, Manta A, Gazouli M, Lyberopoulou A, Lykoudis PM, Polymeneas $\mathrm{G}$, et al. Expression of microRNAs in patients with pancreatic cancer and its prognostic significance. Pancreas. 2013;42(1):67-71.

15. Volinia S, Galasso M, Sana ME, Wise TF, Palatini J, Huebner K, et al. Breast cancer signatures for invasiveness and prognosis defined by deep sequencing of microRNA. Proc Natl Acad Sci USA. 2012;109(8):3024-9.

16. Ying Q, Liang L, Guo W, Zha R, Tian Q, Huang S, et al. Hypoxia-inducible microRNA-210 augments the metastatic potential of tumor cells by targeting vacuole membrane protein 1 in hepatocellular carcinoma. Hepatology. 2011;54(6):2064-75. 
17. Qu A, Du L, Yang Y, Liu H, Li J, Wang L, et al. Hypoxia-inducible MiR-210 is an independent prognostic factor and contributes to metastasis in colorectal cancer. PLoS One. 2014;9(3):e90952.

18. Chen J, Wang W, Zhang Y, Chen Y, Hu T. Predicting distant metastasis and chemoresistance using plasma miRNAs. Med Oncol. 2014;31(1):799.

19. Ozata DM, Caramuta S, Velazquez-Fernandez D, Akcakaya P, Xie H, Hoog $A$, et al. The role of microRNA deregulation in the pathogenesis of adrenocortical carcinoma. Endocr Relat Cancer. 2011;18(6):643-55.

20. Szabo DR, Luconi M, Szabo PM, Toth M, Szucs N, Horanyi J, et al. Analysis of circulating microRNAs in adrenocortical tumors. Lab Invest J Tech Methods Pathol. 2014;94(3):331-9.

21. Tsuchiya S, Fujiwara T, Sato F, Shimada Y, Tanaka E, Sakai Y, et al. MicroRNA-210 regulates cancer cell proliferation through targeting fibroblast growth factor receptor-like 1 (FGFRL1). J Biol Chem. 2011;286(1):420-8.

22. Giannakakis A, Sandaltzopoulos R, Greshock J, Liang S, Huang J, Hasegawa K, et al. miR-210 links hypoxia with cell cycle regulation and is deleted in human epithelial ovarian cancer. Cancer Biol Ther. 2008;7(2):255-64.

23. Qiu S, Lin S, Hu D, Feng Y, Tan Y, Peng Y. Interactions of miR-323/miR-326/ miR-329 and miR-130a/miR-155/miR-210 as prognostic indicators for clinical outcome of glioblastoma patients. J Transl Med. 2013;11(1):10.

24. Hong L, Yang J, Han Y, Lu Q, Cao J, Syed L. High expression of miR-210 predicts poor survival in patients with breast cancer: a meta-analysis. Gene. 2012;507(2):135-8.

25. Camps C, Buffa FM, Colella S, Moore J, Sotiriou C, Sheldon H, et al. hsamiR-210 Is induced by hypoxia and is an independent prognostic factor in breast cancer. Clin Cancer Res. 2008;14(5):1340-8.

26. Greither T, Grochola LF, Udelnow A, Lautenschlager C, Wurl P, Taubert H. Elevated expression of microRNAs 155, 203, 210 and 222 in pancreatic tumors is associated with poorer survival. Int J Cancer. 2010;126(1):73-80.

27. Gee HE, Camps C, Buffa FM, Patiar S, Winter SC, Betts G, et al. hsa-mir-210 is a marker of tumor hypoxia and a prognostic factor in head and neck cancer. Cancer. 2010;116(9):2148-58.

28. Lai NS, Dong QS, Ding H, Miao ZL, Lin YC. MicroRNA-210 overexpression predicts poorer prognosis in glioma patients. J Clin Neurosci Off J Neurosurg Soc Australas. 2014;21(5):755-60.

29. Eilertsen M, Andersen S, Al-Saad S, Richardsen E, Stenvold H, Hald SM, et al. Positive prognostic impact of miR-210 in non-small cell lung cancer. Lung Cancer. 2014;83(2):272-8.

30. McCormick RI, Blick C, Ragoussis J, Schoedel J, Mole DR, Young AC, et al. miR210 is a target of hypoxia-inducible factors 1 and 2 in renal cancer, regulates ISCU and correlates with good prognosis. Br J Cancer. 2013;108(5):1133-42.

31. Mei Y, Gao C, Wang K, Cui L, Li W, Zhao X, et al. Effect of microRNA-210 on prognosis and response to chemotherapeutic drugs in pediatric acute lymphoblastic leukemia. Cancer Sci. 2014;105(4):463-72.

32. Fasanaro P, D'Alessandra Y, Di Stefano V, Melchionna R, Romani S, Pompilio $\mathrm{G}$, et al. MicroRNA-210 modulates endothelial cell response to hypoxia and inhibits the receptor tyrosine kinase ligand Ephrin-A3. J Biol Chem. 2008;283(23):15878-83.

33. Yang W, Sun T, Cao J, Liu F, Tian Y, Zhu W. Downregulation of miR-210 expression inhibits proliferation, induces apoptosis and enhances radiosensitivity in hypoxic human hepatoma cells in vitro. Exp Cell Res. 2012;318(8):944-54.

34. Chio CC, Lin JW, Cheng HA, Chiu WT, Wang YH, Wang JJ, et al. MicroRNA-210 targets antiapoptotic BCl-2 expression and mediates hypoxia-induced apoptosis of neuroblastoma cells. Arch Toxicol. 2013:87(3):459-68.

35. Bertero T, Grosso S, Robbe-Sermesant K, Lebrigand K, Henaoui IS, Puissegur MP, et al. "Seed-milarity" confers to hsa-miR-210 and hsa-miR-147b similar functional activity. PLoS One. 2012;7(9):e44919.

36. Nakada C, Tsukamoto Y, Matsuura K, Nguyen TL, Hijiya N, Uchida T, et al. Overexpression of miR-210, a downstream target of HIF1alpha, causes centrosome amplification in renal carcinoma cells. J Pathol. 2011;224(2):280-8.

37. Puissegur MP, Mazure NM, Bertero T, Pradelli L, Grosso S, Robbe-Sermesant K, et al. miR-210 is overexpressed in late stages of lung cancer and mediates mitochondrial alterations associated with modulation of HIF-1 activity. Cell Death Differ. 2011;18(3):465-78.

38. Pinon JD, Labi V, Egle A, Villunger A. Bim and Bmf in tissue homeostasis and malignant disease. Oncogene. 2008;27(Suppl 1):S41-52.

39. Chan SY, Zhang YY, Hemann C, Mahoney CE, Zweier JL, Loscalzo J. MicroRNA-210 controls mitochondrial metabolism during hypoxia by repressing the iron-sulfur cluster assembly proteins ISCU1/2. Cell Metab. 2009;10(4):273-84

40. Favaro E, Ramachandran A, McCormick R, Gee H, Blancher C, Crosby M, et al. MicroRNA-210 regulates mitochondrial free radical response to hypoxia and krebs cycle in cancer cells by targeting iron sulfur cluster protein ISCU. PLoS One. 2010;5(4):e10345.

41. Yoshioka Y, Kosaka N, Ochiya T, Kato T. Micromanaging iron homeostasis: hypoxia-inducible micro-RNA-210 suppresses iron homeostasis-related proteins. J Biol Chem. 2012;287(41):34110-9.

42. Chen Z, Li Y, Zhang H, Huang P, Luthra R. Hypoxia-regulated microRNA-210 modulates mitochondrial function and decreases ISCU and COX10 expression. Oncogene. 2010;29(30):4362-8.

43. Prasad V, Chandele A, Jagtap JC, Kumar PS, Shastry P. ROS-triggered caspase 2 activation and feedback amplification loop in beta-caroteneinduced apoptosis. Free Radic Biol Med. 2006;41(3):431-42.

44. Tamm C, Zhivotovsky B, Ceccatelli S. Caspase-2 activation in neural stem cells undergoing oxidative stress-induced apoptosis. Apoptosis. 2008;13(3):354-63.

45. Li H, Bergeron L, Cryns V, Pasternack MS, Zhu H, Shi L, et al. Activation of caspase-2 in apoptosis. J Biol Chem. 1997;272(34):21010-7.

46. Slee EA, Harte MT, Kluck RM, Wolf BB, Casiano CA, Newmeyer DD, et al. Ordering the cytochrome c-initiated caspase cascade: hierarchical activation of caspases-2, $-3,-6,-7,-8$, and -10 in a caspase-9-dependent manner. J Cell Biol. 1999;144(2):281-92.

47. Kurokawa H, Nishio K, Fukumoto H, Tomonari A, Suzuki T, Saijo N. Alteration of caspase-3 (CPP32/Yama/apopain) in wild-type MCF-7, breast cancer cells. Oncol Rep. 1999;6(1):33-7.

48. He J, Wu J, Xu N, Xie W, Li M, Li J, et al. MiR-210 disturbs mitotic progression through regulating a group of mitosis-related genes. Nucleic Acids Res. 2013;41(1):498-508.

49. Faraonio R, Salerno P, Passaro F, Sedia C, laccio A, Bellelli R, et al. A set of miRNAs participates in the cellular senescence program in human diploid fibroblasts. Cell Death Differ. 2012;19(4):713-21.

50. Zheng G, Tao Y, Yu W, Schwartz RJ. Brief report: SRF-dependent MiR-210 silences the sonic hedgehog signaling during cardiopoesis. Stem Cells. 2013;31(10):2279-85.

51. Kong LJ, Chang JT, Bild AH, Nevins JR. Compensation and specificity of function within the E2F family. Oncogene. 2007;26(3):321-7.

52. Burhans WC, Heintz NH. The cell cycle is a redox cycle: linking phasespecific targets to cell fate. Free Radic Biol Med. 2009;47(9):1282-93.

53. Zhang $X$, Tang N, Hadden TJ, Rishi AK. Akt, FoxO and regulation of apoptosis. Biochim Biophys Acta. 2011;1813(11):1978-86.

54. Sinha K, Das J, Pal PB, Sil PC. Oxidative stress: the mitochondria-dependent and mitochondria-independent pathways of apoptosis. Arch Toxicol. 2013;87(7):1157-80

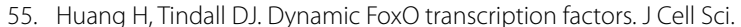
2007;120(Pt 15):2479-87.

56. Luo H, Yang Y, Duan J, Wu P, Jiang Q, Xu C. PTEN-regulated AKT/FoxO3a/ Bim signaling contributes to reactive oxygen species-mediated apoptosis in selenite-treated colorectal cancer cells. Cell Death Dis. 2013;4:e481.

57. Kim JH, Park SG, Song SY, Kim JK, Sung JH. Reactive oxygen speciesresponsive miR-210 regulates proliferation and migration of adiposederived stem cells via PTPN2. Cell Death Dis. 2013:4:e588.

58. Muralimanoharan S, Maloyan A, Mele J, Guo C, Myatt LG, Myatt L. MIR-210 modulates mitochondrial respiration in placenta with preeclampsia. Placenta. 2012;33(10):816-23.

59. Ray PD, Huang BW, Tsuji Y. Reactive oxygen species (ROS) homeostasis and redox regulation in cellular signaling. Cell Signal. 2012;24(5):981-90.

60. Malhotra JD, Kaufman RJ. Endoplasmic reticulum stress and oxidative stress: a vicious cycle or a double-edged sword? Antioxid Redox Signal. 2007;9(12):2277-93.

61. Hockenbery DM, Oltvai ZN, Yin XM, Milliman CL, Korsmeyer SJ. BCl-2 functions in an antioxidant pathway to prevent apoptosis. Cell. 1993;75(2):241-51.

62. Kane DJ, Sarafian TA, Anton R, Hahn H, Gralla EB, Valentine JS, et al. BCl-2 inhibition of neural death: decreased generation of reactive oxygen species. Science. 1993:262(5137):1274-7.

63. Armstrong JS, Jones DP. Glutathione depletion enforces the mitochondrial permeability transition and causes cell death in $\mathrm{BCl}-2$ overexpressing HL60 cells. FASEB J Off Publ Fed Am Soc Exp Biol. 2002;16(10):1263-5.

64. Bouchier-Hayes L, Green DR. Caspase-2: the orphan caspase. Cell Death Differ. 2012;19(1):51-7. 
65. Kumar S. Caspase 2 in apoptosis, the DNA damage response and tumour suppression: enigma no more? Nat Rev Cancer. 2009;9(12):897-903.

66. Guo Y, Srinivasula SM, Druilhe A, Fernandes-Alnemri T, Alnemri ES. Caspase-2 induces apoptosis by releasing proapoptotic proteins from mitochondria. J Biol Chem. 2002;277(16):13430-7.

67. Vaupel P. Hypoxia and aggressive tumor phenotype: implications for therapy and prognosis. Oncologist. 2008;13(Suppl 3):21-6.

68. Huang X, Ding L, Bennewith KL, Tong RT, Welford SM, Ang KK, et al. Hypoxia-inducible mir-210 regulates normoxic gene expression involved in tumor initiation. Mol Cell. 2009;35(6):856-67.

69. Huang X, Le QT, Giaccia AJ. MiR-210-micromanager of the hypoxia pathway. Trends Mol Med. 2010;16(5):230-7.

70. Schmitt M, Pawlita M. High-throughput detection and multiplex identification of cell contaminations. Nucleic Acids Res. 2009;37(18):e119.
71. Castro F, Dirks WG, Fahnrich S, Hotz-Wagenblatt A, Pawlita M, Schmitt M. High-throughput SNP-based authentication of human cell lines. Int J Cancer. 2013;132(2):308-14.

72. Tagscherer KE, Fassl A, Sinkovic T, Combs SE, Roth W. p53-dependent regulation of $\mathrm{MCl}-1$ contributes to synergistic cell death by ionizing radiation and the BCl-2/BCl-XL inhibitor ABT-737. Apoptosis. 2012;17(2):187-99.

73. Fassl A, Tagscherer KE, Richter J, Berriel Diaz M, Alcantara Llaguno SR, Campos B, et al. Notch1 signaling promotes survival of glioblastoma cells via EGFR-mediated induction of anti-apoptotic Mcl-1. Oncogene. 2012;31(44):4698-708.

\section{Submit your next manuscript to BioMed Central and we will help you at every step:}

- We accept pre-submission inquiries

- Our selector tool helps you to find the most relevant journal

- We provide round the clock customer support

- Convenient online submission

- Thorough peer review

- Inclusion in PubMed and all major indexing services

- Maximum visibility for your research

Submit your manuscript at www.biomedcentral.com/submit 